\title{
Long-term persistence of polychlorinated dibenzo-p-dioxins and dibenzofurans in air, soil and sediment around an abandoned pentachlorophenol factory in China
}

\author{
Cheng $\mathrm{Li}^{\mathrm{a}}$, Minghui Zheng ${ }^{\mathrm{a}, *}$, Bing Zhang ${ }^{\mathrm{a}}$, Lirong Gao ${ }^{\mathrm{a}}$, Lidan Liu ${ }^{\mathrm{a}}$, Xin Zhou ${ }^{\mathrm{a}, \mathrm{b}}$, Xiaodong Ma $^{\mathrm{c}}$, Ke Xiao ${ }^{\mathrm{a}}$ \\ a State Key Laboratory of Environmental Chemistry and Ecotoxicology, Research Center for Eco-Environmental Sciences, Chinese Academy of Sciences, P.O. Box 2871, \\ Beijing 100085, China \\ ${ }^{\mathrm{b}}$ Zhejiang Province Environment Monitoring Center, Hangzhou 310000, China \\ ${ }^{\mathrm{c}}$ Tianjin Key Laboratory of Environmental Science and Engineering, Nankai University, Tianjin 300071, China
}

\section{A R T I C L E I N F O}

\section{Article history:}

Received 6 September 2011

Received in revised form

4 November 2011

Accepted 8 November 2011

\section{Keywords:}

Pentachlorophenol

PCDD/Fs

Air soil

Sediment

\begin{abstract}
A B S T R A C T
Air, soils and sediments surrounding an abandoned pentachlorophenol (PCP) factory were sampled to determine the levels of polychlorinated dibenzo-p-dioxins and dibenzofurans (PCDD/Fs), unintentionally formed during PCP production. The mean concentration of PCDD/Fs in ambient air was one order of magnitude higher than that of the reference site. A trend of decreasing concentrations with increasing distance from the factory was observed, suggesting this site has a significant influence on the regional ambient air. As for soil samples collected within $3 \mathrm{~km}$ from the factory and sediment samples from the adjacent rivers, high levels of contamination were found with WHO-TEQ concentrations of $193 \pm 211 \mathrm{pg} /$ $\mathrm{g}$ and $667 \pm 978 \mathrm{pg} / \mathrm{g}$, respectively. The PCDD/F homologue profiles of all samples were consistent with those found in the technical product of PCP, with OCDD as the dominant congener. These results indicate $\mathrm{PCDD} / \mathrm{Fs}$ in the historical contaminated site pose a long-term impact on surrounding environment.
\end{abstract}

(c) 2011 Elsevier Ltd. All rights reserved.

\section{Introduction}

The current concern about polychlorinated dibenzo-p-dioxins and dibenzofurans (PCDD/Fs) is predominantly focused on thermal sources such as metallurgy, secondary metal industries, the open burning of e-waste, and biomass and municipal waste incineration (Weber et al., 2008a). However, historical activities in the chlorine based chemical industry have also released large amounts of PCDD/ Fs to the environment. These historic PCDD/F sources greatly exceed the emissions from contemporary thermal sources (Weber et al., 2008b). In particular, the production of pentachlorophenol (PCP) and sodium pentachlorophenate (Na-PCP) have been recognized as a major historic source of PCDD/Fs (Alcock and Jones, 1997; Masunaga et al., 2001). During PCP (Na-PCP) production, PCDD/Fs (mainly hepta- and octa- substituted PCDD/Fs) were unintentionally generated. The improper disposal of these chemicals and chemical waste originating from production processes has created the major PCDD/F contaminated sites around the world (Alcock and Jones, 1997). Consequently, the potential environmental legacy from these sites remains a great concern. Further, PCDD/Fs can be transported from contaminated sites via volatilization or particle-

\footnotetext{
* Corresponding author.

E-mail address: zhengmh@rcees.ac.cn (M. Zheng).
}

bound transport to the atmospheric environment as secondary sources (DuarteDavidson et al., 1997). However, information on the levels of PCDD/Fs in atmosphere surrounding deserted PCP plants is scarce.

In China, PCP and Na-PCP were produced in the past, mainly for use as a fungicide and wood preservative. Dagu Chemical Plant, located on the bank of the Haihe River in Tanggu District, Tianjin, was the biggest PCP and Na-PCP manufacturer in China. The peak annual production from this plant was up to 17000 tons per year. Bao et al. (1995) reported that PCDD/F concentrations in Chinese $\mathrm{PCP}$ and Na-PCP products were 142 and $92 \mathrm{ng} \mathrm{I}-\mathrm{TEQ} / \mathrm{g}$, respectively. However, the majority of PCDD/Fs generated during PCP production remained in the waste residues. In 1994, PCDD/F levels in the thermolysis waste from PCP (Na-PCP) production at Dagu Chemical Plant were investigated (Bao et al., 1994), and very high TEQ concentrations, in the range of $612-924 \mu \mathrm{g} \mathrm{I}-\mathrm{TEQ} / \mathrm{g}$, were detected. Due to poor treatment measures, a thousand tons of the waste had been discharged into the surrounding environment. Consequently, high levels of PCDD/Fs were detected in the ambient environment, with a study in 1997 showing that soils around the plant and sediments in an adjacent river were heavily contaminated with PCDD/Fs (Luksemburg et al., 1997). The I-TEQ concentrations in the surrounding environment ranged from 15 to $740000 \mathrm{pg} / \mathrm{g}$ in soils and from 150 to $110000 \mathrm{pg} / \mathrm{g}$ in sediments, making this the most highly PCDD/F contaminated site in China. 
PCP and Na-PCP manufacture was discontinued at this chemical plant in 2003 after almost 50 years of operation, and basic remedial measures including the removal of the most heavily contaminated soils and capping the surface waste residues with noncontaminated soils have been carried out. However, due to technical difficulties and the expense of remedial measures, large amounts of waste residues are still present in this area. Consequently, this historical contaminated site appears to represent both a current and future risk to the surrounding environment. Historical investigations on the status of this contaminated site had been focused on samples from the waste residues, soils and sediments collected within and around the plant when PCP (Na-PCP) was still being produced (Bao et al., 1994; Luksemburg et al., 1997; 2001). However, few data are available to assess the current environmental effect of this historical contaminated site.

In this study, an extensive analysis of PCDD/Fs in various environmental samples (atmosphere, soils and sediments) in relation to their distance from the former PCP factory was conducted, also comparing the data with a corresponding residential area in Tianjin. The objective of this study was to evaluate the current environmental impact of PCDD/Fs in the historical contaminated site.

\section{Materials and methods}

\subsection{Sampling}

\subsubsection{Sampling areas}

The abandoned PCP plant is located near a residential area along the Haihe River in Tanggu District, Tianjin, a coastal region with approximately 500000 people. In this study, air, soil and sediment samples were collected around this factory in Tanggu District. The residential area of Tianjin City (50 km from this factory) has a negligible amount of industrial PCDD/F sources, and was used as reference site for comparison. The prevailing wind direction during the sampling period was observed to be from east and southeast, with the average speed of $4.5 \mathrm{~m} / \mathrm{s}$. Four atmospheric sampling sites (A1-A4) were selected approximately 7, 2.5, 2 and $1.5 \mathrm{~km}$ away from the historical PCP factory, respectively, in the residential areas of Tanggu and one sampling site was established in the reference area. Two to five atmosphere samples were collected at each site for analysis. A total of eight soil samples were also collected, six of which (S1-S6) were from within an approximate $3 \mathrm{~km}$ radius of the PCP plant, with the remaining two samples taken from the reference site in Tianjin.

There are two main rivers near the former PCP plant, the Haihe River and the Dagu Drainage River. Haihe River is the largest river system in North China and was an important water source for Tianjin. To reduce the amount of pollution in the Haihe River, the Dagu Drainage River was excavated to collect domestic and industrial wastewater (Ding et al., 2005). Both rivers empty into Bohai Bay about $10 \mathrm{~km}$ from the Dagu Chemical Plant. Ten river sediment samples were collected in this study from the Haihe River (H1-H3) and the Dagu Drainage River (DG1-DG7) adjacent to and within $5 \mathrm{~km}$ downstream of the chemical plant. To also assess the environmental impact of this plant on Bohai Bay, four coastal sediment samples were collected in Bohai Bay (BH1-BH4) near the mouths of the Haihe and Dagu Drainage rivers. All samples were collected during June to August, 2010. Fig. 1 shows the location of all sampling sites.

\subsubsection{Sampling method}

Ambient air samples were collected using high volume samplers (Echo Hi-Vol, Tecora Co. Italy) in accordance with US-EPA Method TO-9A. Particulate phase PCDD/Fs were collected onto cleaned glass fiber filters (GFF) $102 \mathrm{~mm}$ in diameter, while the gas phase PCDD/Fs were adsorbed onto polyurethane foam (PUF), $63 \mathrm{~mm}$ diameter and $76 \mathrm{~mm}$ length. Prior to sampling, the GFFs were baked at $450{ }^{\circ} \mathrm{C}$ to remove organic contaminants, and the PUFs were extracted with acetone in an accelerated solvent extraction (ASE) system (Dionex 350). The air sampling flowing rate was $0.22 \mathrm{~m}^{3} / \mathrm{min}$, as specified, and each sample was collected continuously for $48 \mathrm{~h}$ under consistent weather conditions without rain. The sampling volumes were normalized to the standard conditions of $760 \mathrm{~mm} \mathrm{Hg}$ and $298 \mathrm{~K}$. After sampling, the GFFs and PUFs were tightly wrapped, separately, in aluminum foil and packed in sealed polyethylene bags to avoid contamination and loss.

Surface soil samples (depth $0-10 \mathrm{~cm}$ ) were collected using a pre-cleaned stainless steel shovel. Surface sediments (depth $0-10 \mathrm{~cm}$ ) were taken with a grab sampler (Ekman Grab Sampler, Wildlife Supply Company, US) either from a boat or a bridge. The soil and sediment samples were wrapped in solvent-cleaned aluminum foil and stored at $-20^{\circ} \mathrm{C}$, then were freeze dried as soon as possible for analysis.

\subsection{Sample preparation and analysis}

The preparation and analysis of the samples were conducted in accordance with US-EPA Method 1613B for seventeen 2,3,7,8-substituted PCDD/Fs. Prior to extraction, the GFF and PUF plug which had collected the target compounds from ambient air were combined together, and $10 \mathrm{~g}$ subsamples of dried soil or sediment were homogenized. All samples were spiked with known amounts of ${ }^{13} \mathrm{C}_{12}$-PCDD/F internal standards (Wellington Laboratories, Canada). The samples were then extracted by ASE using hexane: dichloromethane 1:1. The extracts were concentrated using a rotary evaporator (Heidolph, Germany) and were then cleaned up

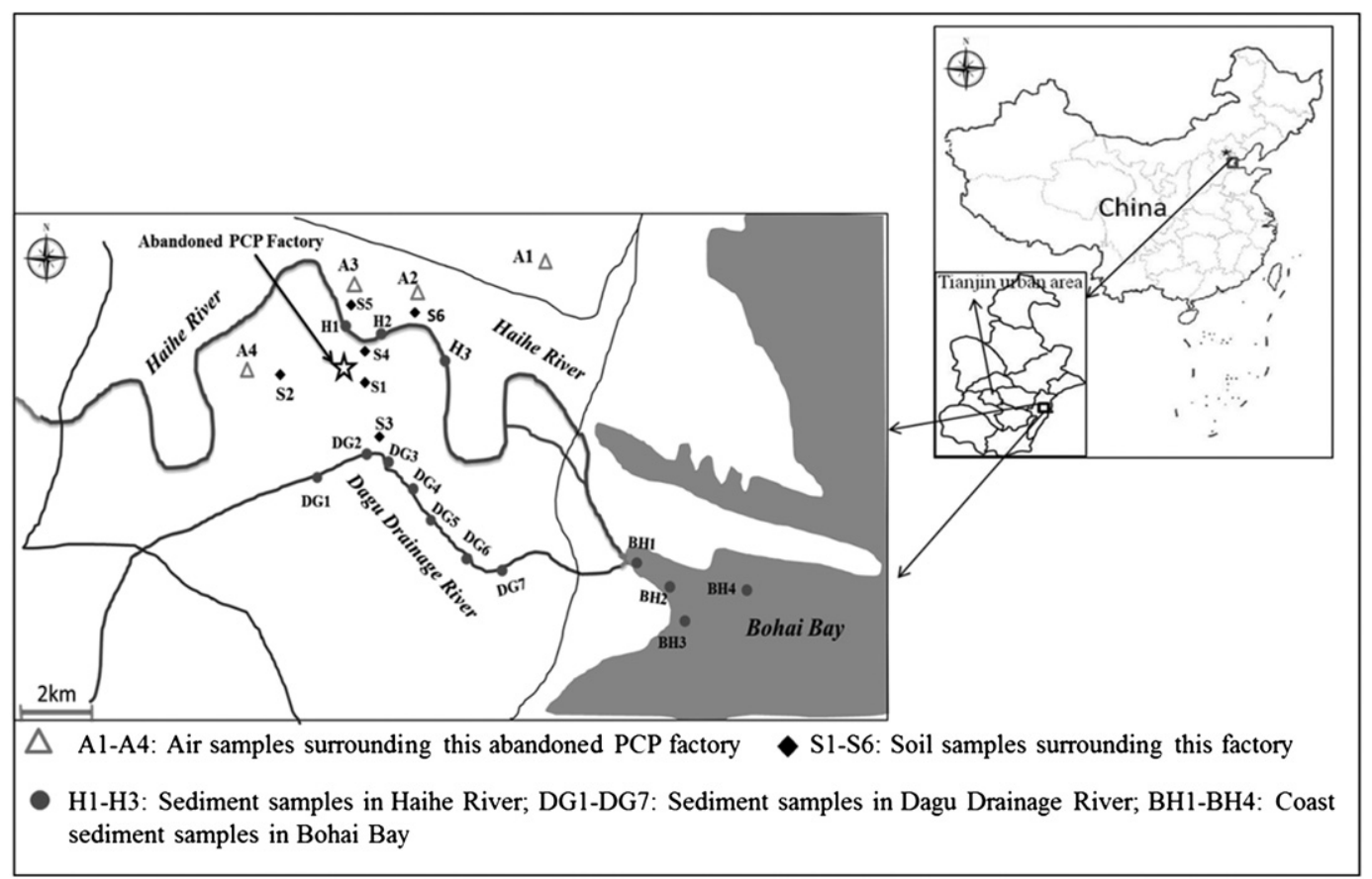

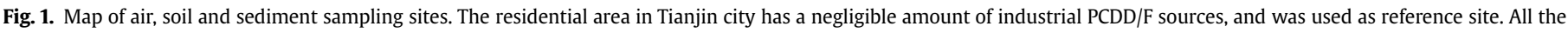
air, soil and sediment samples were collected during June to August, 2010. 
with a silica gel column (treated with $44 \%$ sulfuric acid) and multi-layer silica columns. The PCDD/Fs were fractionated on a basic alumina column and were concentrated to about $20 \mu \mathrm{L}$ by rotary evaporator followed by a gentle stream of nitrogen. The final extracts were spiked with ${ }^{13} \mathrm{C}_{12}$-labeled PCDD/Fs standards for quantification prior to injection onto a high resolution gas chromatograph with detection by a high resolution mass spectrometer (HRGC/HRMS).

The PCDD/Fs were analyzed using an Agilent 6890 gas chromatograph (Agilent USA) coupled with an Autospec Ultima high resolution mass spectrometer (Waters, USA). Chromatographic separation was achieved with a DB-5MS fused-silica column ( $60 \mathrm{~m}, 0.25 \mathrm{~mm}$ i.d. x $0.25 \mu \mathrm{m}$ ) (Agilent, USA). The gas chromatograph was operated in splitless mode with $1 \mu \mathrm{L}$ of sample solution injected by a CTC PAL auto-sampler. Helium was used as the carrier gas with a constant flow of $1.2 \mathrm{~mL} / \mathrm{min}$. The mass spectrometer was operated with positive electron impact ionization (EI+) in the selective ion monitoring (SIM) mode, with a resolution of 10000 and an electron impact energy of $38 \mathrm{eV}$.

\subsection{Quality assurance and quality control $(Q A / Q C)$}

In the ambient air sampling, a second PUF was located in series with the first PUF to confirm that no breakthrough had occurred. Field and laboratory blanks were performed routinely and the values were acceptable for the required methods for different kinds of samples. The recoveries of the ${ }^{13} \mathrm{C}_{12}$-labeled PCDD/F internal standards were in the range of $40-126 \%$, which was acceptable for Method 1613B. The limit of detection (LOD) in this study was defined as three times the signal/noise $(\mathrm{S} / \mathrm{N})$ ratio. Where concentrations were below the LOD, a value of half the LOD was used to calculate the total concentrations and TEQs.

\section{Results and discussion}

\subsection{Concentrations and distribution of PCDD/Fs in ambient air}

Table 1 lists the mean concentrations of the individual PCDD/F congeners and the TEQs in ambient air, soils and sediments. Tables S1-S3 in the Supplementary material include detailed PCDD/F concentrations at each site. For the ambient air samples, the total 2,3,7,8-substituted PCDD/F concentrations in the four samples surrounding the PCP plant (A1-A4) ranged from 2635 to $65506 \mathrm{fg} / \mathrm{m}^{3}$ with a mean value of $29581 \mathrm{fg} / \mathrm{m}^{3}$. The total 2,3,7,8substituted PCDD/F concentration in ambient air at the reference site $50 \mathrm{~km}$ from the plant was $1993 \mathrm{fg} / \mathrm{m}^{3}$, one order of magnitude lower than in the samples from Tanggu District. When compared with ambient air quality data reported in other industrial areas, the mean total PCDD/F concentration around this abandoned PCP plant is higher than in Italy around a municipal solid waste incinerator $\left(1.18-6.06 \mathrm{pg} / \mathrm{m}^{3}\right.$ ) (Colombo et al., 2009); more than 15 times higher than in an industrial area of Taiwan (Wang et al., 2007); and almost 20 times higher than around a steel plant in Northeast China (Li et al., 2010). These results demonstrate that there is a high level PCDD/F contamination in the ambient air around this abandoned PCP plant, and the impact of this contaminated site on ambient air quality is significant.

It is well known that the PCDD/F congeners commonly found as PCP (Na-PCP) impurities, are dominated by OCDD followed by 1,2,3,4,6,7,8-HpCDD and OCDF. Bao et al. (1995) reported that OCDD, $1,2,3,4,6,7,8-\mathrm{HpCDD}$ and OCDF contributed 76\%, 8.5-10\% and $10-12 \%$, respectively, to the total $2,3,7,8$-substituted $\mathrm{PCDD} / \mathrm{Fs}$ present in Chinese technical PCP and Na-PCP products. In the ambient air samples from the Tanggu area, a similar congener profile was observed, with OCDD $(81 \% \pm 8.5 \%$, average \pm standard deviation), $1,2,3,4,6,7,8-\mathrm{HpCDD}(6.7 \% \pm 2.3 \%)$ and $\mathrm{OCDF}(6.3 \pm 2.9 \%)$ dominating the $2,3,7,8$-substituted PCDD/F congeners. The average concentration of these characteristic congeners (Total concentrations of OCDD, 1,2,3,4,6,7,8-HpCDD and OCDF) was approximately 21 times higher than in the reference area. As shown in Fig. 2, a decreasing concentration gradient of these indicative congeners (Total concentrations of OCDD, 1,2,3,4,6,7,8-HpCDD and OCDF) was observed along with increasing distance from this abandoned PCP factory, with: A4 $>$ A3 $>$ A2 $>$ A1 $>$ reference site $\left(63741>35960>12548>2293>1348 \mathrm{fg} / \mathrm{m}^{3}\right.$, respectively). This gradient clearly indicates that the ambient air contamination by PCDD/Fs is from this factory via atmospheric transport. Locations A4, A3 and A2, which are within $2.5 \mathrm{~km}$ of the plant, are significantly influenced by this contaminated site. Moreover, east and southeast winds were prevailing over the sampling periods. The A3 and A4 sites, with higher concentrations of these characteristic PCDD/F congeners (Total concentrations of OCDD, 1,2,3,4,6,7,8-HpCDD and OCDF) are just located in the downwind from the historical area sites. This result reveals that wind directions are probably another factor affecting the levels and distribution of PCDD/Fs in atmosphere.

Generally, PCDD/Fs are characterized by very low vapor pressures and high octanol/water partition coefficients. These properties determine their fate and environmental behavior, with PCDD/ Fs strongly partitioned to soils and sediments, and virtually immobile in the terrestrial environment (Fiedler, 1996). However, the results of this study clearly indicate that PCDD/Fs have been transferred to ambient air from the contaminated site. These legacies imposed a striking impact on the pollution of regional atmosphere as a secondary pollution source. It is conjectured that

Table 1

Mean concentrations and TEQs for PCDD/Fs in air, soils and sediments ${ }^{\mathrm{a}}$.

\begin{tabular}{|c|c|c|c|c|c|c|}
\hline \multirow[t]{2}{*}{ Sampling areas } & \multicolumn{4}{|c|}{ Surrounding the abandoned PCP plant } & \multicolumn{2}{|c|}{ Reference area } \\
\hline & $\operatorname{Air}(n=4)\left(f g / m^{3}\right)$ & Soils $(n=6)(\mathrm{pg} / \mathrm{g})$ & River Sediments $(n=10)(\mathrm{pg} / \mathrm{g})$ & Coastal sediments $(n=4)(\mathrm{pg} / \mathrm{g})$ & Air $\left(\mathrm{fg} / \mathrm{m}^{3}\right)$ & Soils $(n=2)(\mathrm{pg} / \mathrm{g})$ \\
\hline 2378-TCDF & $39.7 \pm 19.3$ & $8.5 \pm 7.8$ & $15.4 \pm 18.8$ & $0.5 \pm 0.38$ & 53.8 & $1.5 \pm 0.92$ \\
\hline 12378-PeCDF & $35.2 \pm 15.3$ & $14.7 \pm 12.8$ & $21.8 \pm 26.5$ & $0.6 \pm 0.6$ & 48 & $1.5 \pm 0.28$ \\
\hline 23478-PeCDF & $45.3 \pm 22$ & $28.2 \pm 26.7$ & $32.3 \pm 36.9$ & $1 \pm 0.53$ & 53.5 & $1.4 \pm 0.92$ \\
\hline $123478-\mathrm{HxCDF}$ & $146 \pm 122$ & $287 \pm 314$ & $1030 \pm 1716$ & $27.7 \pm 18.7$ & 65.1 & $2.6 \pm 1.7$ \\
\hline 123678-HxCDF & $45.6 \pm 22$ & $55.1 \pm 49.8$ & $167 \pm 175$ & $5.3 \pm 5.5$ & 54.1 & $1.4 \pm 0.14$ \\
\hline 234678-HxCDF & $40.1 \pm 12$ & $40.9 \pm 43.1$ & $179 \pm 332$ & $4.8 \pm 5$ & 61.2 & $1 \pm 0.07$ \\
\hline 123789-HxCDF & $16.2 \pm 10.6$ & $19.8 \pm 25.5$ & $37.1 \pm 54.5$ & $1.5 \pm 1.3$ & 11.3 & $0.3 \pm 0$ \\
\hline 1234678-HpCDF & $325 \pm 227$ & $544 \pm 580$ & $2354 \pm 3979$ & $213 \pm 332$ & 207 & $5.3 \pm 3.82$ \\
\hline 1234789-HpCDF & $84.3 \pm 68.2$ & $160 \pm 186$ & $801 \pm 1455$ & $66 \pm 103$ & 31.3 & $1 \pm 0.78$ \\
\hline OCDF & $1317 \pm 954$ & $2003 \pm 2316$ & $14447 \pm 22612$ & $4197 \pm 7374$ & 316 & $12.2 \pm 12.9$ \\
\hline 2378-TCDD & $2.7 \pm 2.1$ & $1.4 \pm 1.41$ & $5.6 \pm 5.2$ & $0.6 \pm 0.87$ & 3.4 & $0.3 \pm 0.07$ \\
\hline 12378-PeCDD & $8.9 \pm 8.5$ & $16.1 \pm 16.5$ & $22 \pm 20.8$ & $2.4 \pm 2.04$ & 10.1 & $0.4 \pm 0.21$ \\
\hline 123478-HxCDD & $16.5 \pm 16.3$ & $49 \pm 56.6$ & $183 \pm 215$ & $14.8 \pm 13.3$ & 8.5 & $0.3 \pm 0.28$ \\
\hline 123678-HxCDD & $92.3 \pm 90.1$ & $317 \pm 372$ & $896 \pm 1352$ & $22.5 \pm 14.6$ & 23 & $1 \pm 0.64$ \\
\hline 123789-HxCDD & $47.8 \pm 47.5$ & $143 \pm 171$ & $224 \pm 239$ & $11.7 \pm 9.11$ & 14.7 & $1 \pm 1.1$ \\
\hline 1234678-HpCDD & $2120 \pm 2327$ & $5829 \pm 7001$ & $26275 \pm 40155$ & $765 \pm 560$ & 186 & $14.5 \pm 15.5$ \\
\hline OCDD & $25198 \pm 24063$ & $41720 \pm 51468$ & $192219 \pm 275181$ & $10805 \pm 9825$ & 846 & $74 \pm 76.5$ \\
\hline Total 2378-PCDD/Fs & $29581 \pm 27989$ & $51231 \pm 53968$ & $238910 \pm 346382$ & $16137 \pm 18133$ & 1993 & $305 \pm 374$ \\
\hline WHO-TEQ & $104 \pm 84.3$ & $193 \pm 211$ & $667 \pm 978$ & $27 \pm 22.7$ & 64.8 & $2.42 \pm 0.45$ \\
\hline
\end{tabular}

\footnotetext{
${ }^{\text {a }}$ Results are shown as mean values \pm standard deviation.
} 


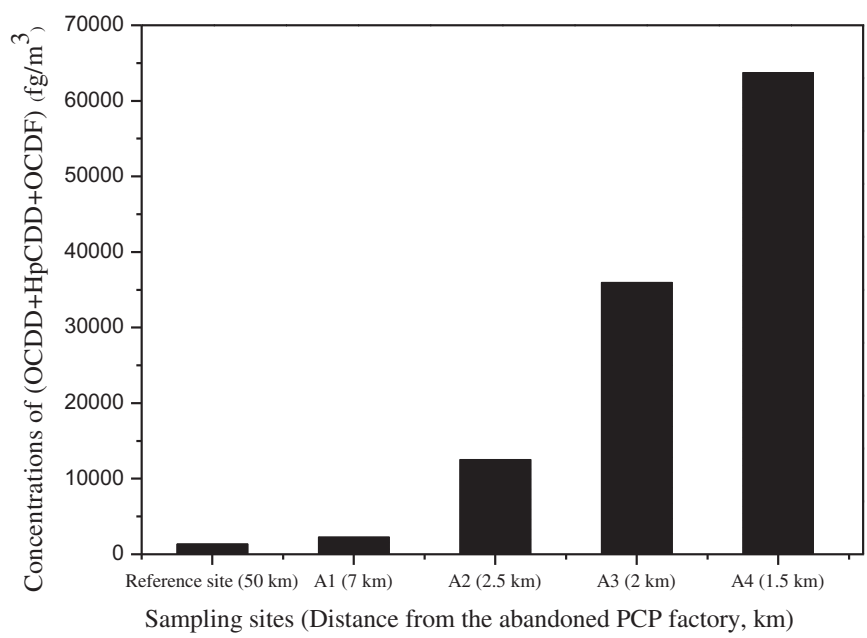

Fig. 2. Total concentrations of $O C D D, H p C D D$ and $O C D F$ in ambient air sampling sites of the reference area, A1, A2, A3 and A4. The sampling sites were 50, 7, 2.5, 2, $1.5 \mathrm{~km}$ away from the abandoned PCP factory, respectively.

there are different pathways for the transfer of PCDD/Fs from this contaminated site to ambient air: via volatilization of gas phase PCDD/Fs; or via particle-bound transport of soil and dust particulates from the terrestrial contamination. In general, the volatility of PCDD/Fs decreases with increasing chlorination, as can see from the vapor pressure of different congeners (Chang et al., 2004). The lower chlorinated congeners (tetra- and penta-CDD/Fs) which have somewhat higher vapor pressures are more readily volatilized. However, for the highly chlorinated congeners, especially the predominant congener in this study, OCDD, the vapor pressure is in the order of $10^{-8} \mathrm{~Pa}$ (Baker and Hites, 2000), so volatilization from soils seems highly unlikely. Thus particulate-bound transport from soils is believed to be the principal pathway for the transport of OCDD into ambient air. In addition to the two pathways described above, Liu et al. (2002) reported it is possible for PCP to react photochemically to form OCDD and HpCDD. Baker and Hites (2000) suggested that available sunlight in the troposphere may convert environmental levels of PCP in the atmosphere to OCDD and lesser amounts of HpCDD. These studies indicate that PCP which has volatilized from the contaminated site may be converted to OCDD and HpCDD in ambient air. It should be noted, however, that elevated concentrations of OCDF, at similar concentrations to HpCDD, were also observed in the air samples, suggesting that the contribution of photochemical synthesis to the OCDD and HpCDD might be neglected.

The WHO 2005 toxic equivalency factors (TEF) values were used to calculate the toxic equivalents (TEQs) for PCDD/Fs. OCDD has a very low TEF of 0.0003 which results in a low contribution by this congener to the total WHO-TEQ in the air samples $(<10 \%)$. Thus, a typical profile from this site, with high levels of OCDD in the air leads to a relatively low TEQ concentrations with an average value of $104 \mathrm{fg}$ WHO-TEQ $/ \mathrm{m}^{3}$ (range: $34.9-214 \mathrm{fg} \mathrm{WHO-TEQ} / \mathrm{m}^{3}$ ), which is only slightly higher than the reference area (64.8 fg WHO-TEQ/ $\mathrm{m}^{3}$ ). The difference between the contaminated site and reference site concentrations were not apparent. The TEQ results suggest that the abandoned PCP factory has a limited impact on the toxicity of the ambient air. Despite this, an extremely high mass of PCDD/Fs (predominantly $\mathrm{Hp}-\mathrm{CDD} / \mathrm{Fs}$ and $\mathrm{OCDD} / \mathrm{F}$ ) would be constantly released to ambient air from this contaminated site, and these PCDD/Fs would be deposited onto ambient soils, plants and water, leading to their entry into the food chain. Therefore, the high concentrations of PCDD/Fs in air released from this contaminated site have important environmental implications.

\subsection{Concentrations and distribution of PCDD/Fs in soils and sediments}

The PCDD/F TEQs in the six soil samples collected around the contaminated site ranged from 48 to $493 \mathrm{pg}$ WHO-TEQ/g dry weight (dw) with a mean value of $193 \mathrm{pg}$ WHO-TEQ/g dw. In contrast, the concentrations in soil samples collected from the reference area ranged from 2.4 to $2.7 \mathrm{pg}$ WHO-TEQ/g dw, a substantially lower amount, suggesting that the soils surrounding this PCP factory are highly contaminated by PCDD/Fs.

The highest concentrations of PCDD/Fs were found in samples S1 and S3 (493 pg WHO-TEQ/g dw and $439 \mathrm{pg}$ WHO-TEQ/g dw, respectively, as shown in Table $\mathrm{S} 2$ ) which were collected from areas to the southeast of the contaminated site which were used as a chemical waste deposition site for the factory in the past. Due to the long-term dumping of waste, PCDD/Fs would be diffused into soils with these chemical waste residues and may be responsible for the severe contamination in these areas. Sites of S5 and S6, which were located in residential areas on the opposite side of the Haihe River (approximately $2 \mathrm{~km}$ away from the site), had PCDD/F levels that were an order of magnitude lower than those at $\mathrm{S} 1$ and S3 with values of $58 \mathrm{pg}$ WHO-TEQ/g dw (S5) and $56 \mathrm{pg}$ WHO-TEQ/g $\mathrm{dw}$ (S6). However, these concentrations are still more than 20 times higher than at the reference sites. As there was no direct pollution by waste material from this site at the S5 and S6 locations, dust particle transportation and precipitation from this chemical plant over a long period of time are probably the main reasons for the elevated PCDD/F levels.

The PCDD/F TEQ concentrations in ten sediment samples collected from the Haihe River and Dagu Drainage River ranged from 136 to $3272 \mathrm{pg}$ WHO-TEQ/g dw with an average of $667 \mathrm{pg}$ WHO-TEQ/g dw. These sediment concentrations are higher than the soil concentrations. This severe contamination of the river sediments adjacent to this abandoned PCP factory means that the PCDD/F levels around this site are much higher than reported in most other sites in China. The mean TEQ concentration in the river sediments was 220 times higher than levels recorded in the Liaohe River (Zhang et al., 2010), 226 times higher than in the Pearl River Delta (Zhang et al., 2009), and was also greater than reported at some $\mathrm{PCDD} / \mathrm{F}$ contamination sites such as Dongting Lake (0.7-11 pg I-TEQ/g) (Gao et al., 2008) and Ya-er Lake (Wu et al., 2001) (10-420 pg I-TEQ/g) in China.

The concentrations in sediments in the Dagu Drainage River (DG1-DG7) were considerably higher than those from the Haihe River (H1-H3) (see Table S3). This result is consistent with the fact that wastewater from this chemical plant was directly discharged into the Dagu Drainage River. Extremely high PCDD/Fs levels (up to $3272 \mathrm{pg}$ WHO-TEQ/g dw) were found at site DG2, located near the discharge point from this abandoned PCP plant. In contrast, at site DG1, located upstream of the chemical plant, the concentrations were much lower (136 pg WHO-TEQ/g dw). In the sites in the downstream of this factory, the PCDD/F concentrations decreased with increasing distance from the discharge point into the Dagu Drainage River. This trend confirms that this abandoned PCP factory was a major source of PCDD/Fs in this river.

The Haihe and Dagu Drainage rivers both flow through a large canal and ultimately empty into Bohai Bay about $10 \mathrm{~km}$ from this chemical plant. It is reasonable to assume that contamination in the two rivers would also influence Bohai Bay, so sediment samples were collected from Bohai Bay near the river mouth estuary. As expected, the PCDD/Fs TEQ concentrations in the four sediment samples from Bohai Bay (BH1-BH4) ranged from 8.4 to $58.7 \mathrm{pg}$ WHO-TEQ/g dw with a mean value of $27.1 \mathrm{pg}$ WHO-TEQ/g dw. These concentrations are higher than those measured at the Qingdao Coastal Sea (0.2-4.2 pg/g TEQ dw) (Pan et al., 2008), and 


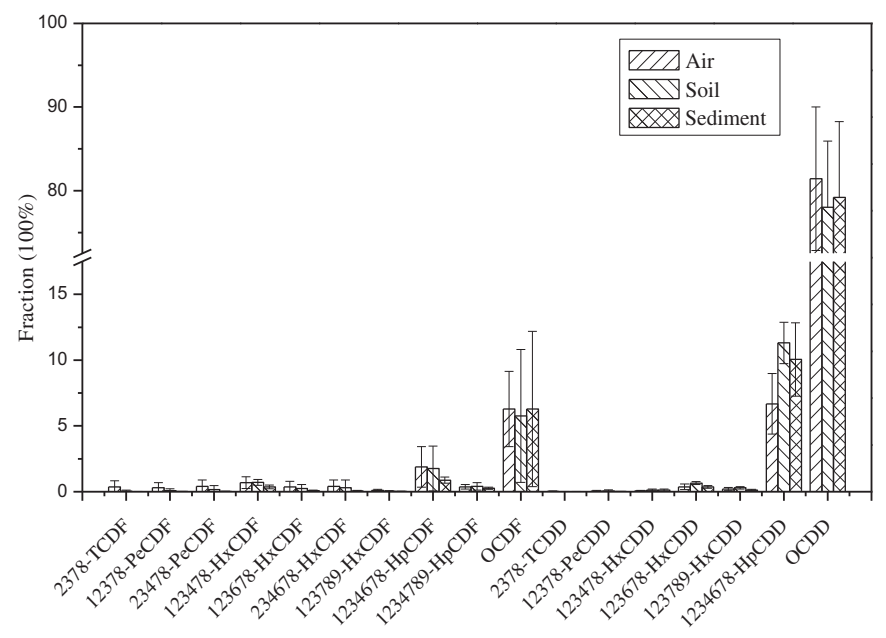

Fig. 3. $P C D D / F$ congener profiles in air, soil and sediment samples surrounding the abandoned PCP factory.

the Yellow River and Yangtze River estuaries (0.11-1.01 WHO-TEQ $\mathrm{pg} / \mathrm{g}$ ) (Hui et al., 2009) in China. Similar congener profiles were found in the river sediment and Bohai Bay sediment samples, suggesting that the $\mathrm{PCDD} / \mathrm{F}$ concentrations in Bohai Bay are contributed by this contaminated site.

To better evaluate the PCDD/F contamination in the sediments, the Canadian Sediment Quality Guidelines (CCME, 2002) were adopted. Two guideline values have been developed: Probable Effect Levels (PELs) which represent the concentration above which adverse ecological effects are likely to occur; and the Interim Sediment Quality Guidelines (ISQGs) which are the value below which adverse effects on sediment fauna are unlikely. The PELs and ISQGs for PCDD/Fs are $21.5 \mathrm{pg}$ TEQ/g and $0.85 \mathrm{pg}$ TEQ/g respectively. In this study, the TEQ concentrations in all the river sediment samples exceeded the PEL, and the mean concentration was more than 30 times above the PEL. In the sediments from Bohai Bay, the TEQ values for all samples exceeded the ISQG, and the concentrations in two samples were also above the PEL. These results imply that PCDD/Fs were very persistent in sediments in both rivers and Bohai Bay and the elevated concentrations are likely to result in the bioaccumulation of PCDD/Fs with higher levels occurring in the aquatic food chain which may pose a potential risk to aquatic life.

The homologue profile of PCDD/Fs in soils and sediments surrounding this site closely match the "fingerprint" homologue profile of PCDD/Fs in PCP (Na-PCP) impurities and are also similar to the PCDD/Fs profile in the air samples in this study (Fig. 3). OCDD is the dominant congener, contributing an average of $78 \%$ of the total $2,3,7,8$-substituted PCDD/Fs in soil and $79.1 \%$ in the sediment. The next most abundant congeners were $1,2,3,4,6,7,8-\mathrm{HpCDD}$ (12\% and $11 \%$ on average in soil and sediment, respectively) and OCDF (7.5\% and $6 \%$ on average). Further, the congener profile determined in this study was similar to that in Dongting Lake which was contaminated by the use of Na-PCP (Gao et al., 2008), where OCDD contributed $74-97 \%$ to the total 2,3,7,8-substituted PCDD/F concentrations. The congener pattern measured in this study further confirms that PCP (Na-PCP) production at this chemical plant is the main source of $\mathrm{PCDD} / \mathrm{F}$ contamination in this regional environment.

\section{Conclusions}

The results of this study indicate that $\mathrm{PCDD} / \mathrm{F}$ pollution in ambient air, soil and sediment was found surrounding the abandoned PCP factory. Bohai Bay, $10 \mathrm{~km}$ from the site, is also influenced by this historical PCDD/F source. Despite the production of PCP was discontinued for several years, residues of PCDD/Fs are still strongly persistent in various environmental compartments surrounding this factory, with a significant impact on regional environment. Furthermore, this study presents clear evidence that the historical contaminated site can serve as a secondary pollution source of PCDD/Fs and provide a long-term release of these pollutants into ambient air. Therefore, monitoring and further remediation of these historical contaminated sites is likely to become an emergent issue.

\section{Acknowledgments}

This study was financially supported by the Chinese Academy of Sciences (Grant KZXZ-YW-JS406), National 973 program (2009CB421606), the Ministry of Science and Technology of China (2008FY210100) and National Natural Science Foundation of China (21007084, 20921063).

\section{Appendix. Supplemental material}

Supplementary information associated with this article can be found, in the online version, at doi:10.1016/j.envpol.2011.11.015.

\section{References}

Alcock, R.E., Jones, K.C., 1997. Pentachlorophenol (PCP) and chloranil as PCDD/F sources to sewage sludge and sludge amended soils in the UK. Chemosphere 35 , 2317-2330.

Baker, J.I., Hites, R.A., 2000. Is combustion the major source of polychlorinated dibenzo-p-dioxins and dibenzofurans to the environment? A mass balance investigation. Environmental Science \& Technology 34, 2879-2886.

Bao, Z., Wang, K., Kang, J., Zhao, L., 1994. Analysis of 2, 3, 7, 8- substituted PCDDs and PCDFs in thermolysis waste of $\mathrm{HCH}$. Environmental Chemistry 13, 409-414 (in Chinese).

Bao, Z., Wang, K., Kang, J., Zhao, L., 1995. Analysis of polychlorinated dibenzo-pdioxins and polychlorinated dibenzofurans in pentachloro-phenol and sodium pentachlorophenate. Environmental Chemistry 14, 317-321 (in Chinese).

CCME (Canadian Council of Ministry of the Environment), 2002. Canadian Environmental Quality Guidelines for Polychlorinated Dibenzo-p-dioxins and Polychlorinated Dibenzofurans (PCDD/Fs).

Chang, M.B., Chi, K.H., Chang-Chien, G.P., 2004. Evaluation of PCDD/F congener distributions in MWI flue gas treated with SCR catalysts. Chemosphere 55, 1457-1467.

Colombo, A., Benfenati, E., Mariani, G., Lodi, M., Marras, R., Rotella, G., Senese, V., Fattore, E., Fanelli, R., 2009. PCDD/Fs in ambient air in north-east Italy: the role of a MSWI inside an industrial area. Chemosphere 77, 1224-1229.

Ding, H., Li, X.G., Liu, H., Wang, J., Shen, W.R., Sun, Y.C., Shao, X.L., 2005. Persistent organochlorine residues in sediments of Haihe River and Dagu Drainage River in Tianjin, China. Journal of Environmental Sciences-China 17, 731-735.

DuarteDavidson, R., Sewart, A., Alcock, R.E., Cousins, I.T., Jones, K.C., 1997. Exploring the balance between sources, deposition, and the environmental burden of PCDD/Fs in the UK terrestrial environment: an aid to identifying uncertainties and research needs. Environmental Science \& Technology 31,1-11.

Fiedler, H., 1996. Sources of PCDD/PCDF and impact on the environment. Chemosphere 32, 55-64.

Gao, L.R., Zheng, M.H., Zhang, B., Liu, W.B., Zhao, X.R., Zhang, Q.H., 2008. Declining polychlorinated dibenzo-p-dioxins and dibenzofurans levels in the sediments from Dongting Lake in China. Chemosphere 73, S176-S179.

Hui, Y.M., Zheng, M.H., Liu, Z.T., Gao, L.R., 2009. PCDD/Fs and dioxin-like PCBs in sediments from Yellow Estuary and Yangtze Estuary, China. Bulletin of Environmental Contamination and Toxicology 83, 614-619.

Li, Y.M., Wang, P., Ding, L., Li, X.M., Wang, T., Zhang, Q.H., Yang, H.B., Jiang, G.B., Wei, F.S., 2010. Atmospheric distribution of polychlorinated dibenzo-p-dioxins, dibenzofurans and dioxin-like polychlorinated biphenyls around a steel plant Area, Northeast China. Chemosphere 79, 253-258.

Liu, P.Y., Zheng, M.H., Xu, X.B., 2002. Phototransformation of polychlorinated dibenzo-p-dioxins from photolysis of pentachlorophenol on soils surface. Chemosphere 46, 1191-1193.

Luksemburg, W.J., Mitzel, R., Hedin, J., Silverbush, B., Wong, A., Zhou, H., 1997 Polychlorinated and dibenzofurans (PCDDs/PCDFs) levels in environmental and human hair samples around a pentachlorophenol plant in China. Organohalogen Compounds 32, 38-40.

Luksemburg, W.J., Wong, A.S., Maier, M.M., Spas, R.A.A., Zhou, H., 2001. A follow-up study of polychlorinated dibenzodioxin and dibenzofuan near a pesticide plant in Dagu, China. Organohalogen Compounds 51, 223-225.

Masunaga, S., Takasuga, T., Nakanishi, J., 2001. Dioxin and dioxin-like PCB impurities in some Japanese agrochemical formulations. Chemosphere 44, 873-885. 
Pan, J., Yang, Y.-L., Chen, D.-Z., Xu, Q., Tang, H., Li, Y., Nie, L.-M., Jiang, K., Xi, D.-L., 2008. Distribution characteristics and source analysis of dioxins in sediments and mussels from Qingdao coastal sea. Chemosphere 70, 1699-1706.

Wang, L.-C., Tsai, C.-H., Chang-Chien, G.-P., Hung, C.-H., 2007. Characterization of polybrominated dibenzo-p-dioxins and dibenzofurans in different atmospheric environments. Environmental Science \& Technology 42, 75-80.

Weber, R., Gaus, C., Tysklind, M., Johnston, P., Forter, M., Hollert, H., Heinisch, E. Holoubek, I., Lloyd-Smith, M., Masunaga, S., Moccarelli, P., Santillo, D., Seike, N., Symons, R., Torres, J., Verta, M., Varbelow, G., Vijgen, J., Watson, A., Costner, P. Woelz, J., Wycisk, P., Zennegg, M., 2008a. Dioxin- and POP-contaminated sites-contemporary and future relevance and challenges. Environmental Science and Pollution Research 15, 363-393.
Weber, R., Tysklind, M., Gaus, C., 2008b. Dioxin - contemporary and future challenges of historical legacies. Environmental Science and Pollution Research 15, 96-100.

Wu, W.Z., Schramm, K.W., Xu, Y., Kettrup, A., 2001. Mobility and profiles of polychlorinated dibenzo-p-dioxins and dibenzofurans in sediment of Ya-Er Lake, China. Water Research 35, 3025-3033.

Zhang, S.K., Peng, P.A., Huang, W.L., Li, X.M., Zhang, G., 2009. PCDD/PCDF pollution in soils and sediments from the Pearl River Delta of China. Chemosphere 75 1186-1195.

Zhang, H.J., Zhao, X.F., Ni, Y.W., Lu, X.B., Chen, J.P., Su, F., Zhao, L., Zhang, N., Zhang, X.P., 2010. PCDD/Fs and PCBs in sediments of the Liaohe River, China: levels, distribution, and possible sources. Chemosphere 79, 754-762. 